\title{
CLIL AS A METHOD IN TEACHING SPORT COLLEGE STUDENTS THROUGH BILINGUAL CLASS PROGRAM
}

\author{
Limpad Nurrachmad \\ Universitas Negeri Semarang, Indonesia
}

\begin{abstract}
The internationalization of institutions proclaimed by Universitas Negeri Semarang has led to the emergence of bilingual class program in every study program. The challenge faced when there are bilingual classes is the ability of lecturers in several majors to provide courses in both English and Bahasa. This study aims at answering the challenges currently faced by UNNES when providing a bilingual class. Then, it is to illustrate and describe the implementation of Content and Language Integrated Learning (CLIL) on the tennis class at the Faculty of Sport Science. The result show that combination of CLIL and SFL was chosen because CLIL teaching method has two simultaneous focuses on content and language while SFL is a teaching method emphasizing the deconstruction of academic genres texts as well as explicit teaching on text features. It is expected that the combination of the two can produce teaching methods that emphasize course material and mastery of English as a medium of instruction in a balance and easier to understand due to the explicit deconstruction of academic texts.
\end{abstract}

Key words: CLIL, bilingual, tennis, SFL

\section{INTRODUCTION}

Teaching English has now been devoted to meet the specific needs of each discipline, for example: Engineering English, English in sports, English in Medicine, Business and Economics English, etc. Teaching English in those fields/disciplines is commonly referred to as English for Special Purposes (ESP). The current ESP field is also highly developed into Content and Language Integrated Learning (CLIL), which means teaching each subject line using English as the medium of instruction.

CLIL itself has become a trend of English teaching that is commonly applied in Europe and there is a change of name to Sheltered Instruction (SI) in America. This English teaching technique is considered to be able to bridge the learner's need to acquire learning content in each field of study and English. If viewed from the aspect of language, the application of CLIL itself is in line with the central principle of communicative language learning which aims to place language learning in a meaningful context for learners (Finocchiaro and Brumfit, 1983). While if it is viewed from the pedagogical science, CLIL is an approach in response to the necessity for integrating education in both university subjects and language skills (Rubtcova and Valentina, 2016).

The Context of education in Indonesia is now moving in the process of internationalization of institutions, especially the Semarang State University (UNNES). UNNES in the framework of internationalization of institutions has been in cooperation with overseas universities such as Australia, Thailand, Turkey, Philippines, Denmark, etc. There are various programs developed to promote UNNES as one of international reputed universities in Indonesia such as Darmasiswa, Sports Student Exchange, Overseas Internship Program, and not to mention Bilingual Class. 
To bridge the bilingual class students, then the instructional materials should be delivered in both English and Bahasa Indonesia properly. At UNNES, the teaching of subjects that use English language of the special field is still implemented in general and is not devoted to meet the needs and context of the learners, especially in bilingual class program. They have not been adequately linked to the use of English in the context of the field of science so that there is no connection between English language materials is taught in general with the field which the students learn. It also leads to less contextual learning and less meaningful for students. This results in low motivation of learners because they do not see any relationship between the mastery of English with the field they learn.

Application of more contextual English learning through CLIL also must be equipped with a more appropriate method in terms of learning academic text for students. Therefore, this paper would describe the result of the small-scale study carried out among the $2^{\text {nd }}$ year students of bilingual class at the Sport Science Department, UNNES. It was to examine how CLIL based on systemic functional linguistics could be implemented in a tennis bilingual class. The study was also an attempt to know the response of bilingual students towards the implementation of CLIL in the class. The paper then was supposed to be a guideline for lecturers who teach bilingual classes as the process of supporting internalization programs.

\section{LITERATURE REVIEW}

\section{Bilingual Education}

Bilingual education is a model of the use of two languages to convey curriculum materials with the aim of strengthening the students' competence in foreign languages. By using this model there are two main things that students get, namely the mastery of content itself and speaking mastery in two languages. Learning a language is learning how to express intentions in an environmental context. The wider the social environment, the need for mastery of language with all its complexity will be increasing as well. Cohen (1985) states that "bilingual education" is the application of two languages as media of instruction for a learner or a group of learners in part or all of the school curriculum. It is similarly acknowledged that it is impossible to completely separate language and culture. Accordingly, the term bilingual education includes the concept of bicultural education (Ovando and Collier 1985).

\section{Content and Language Integrated Learning}

The term Content and Language Integrated Learning or CLIL was created by Coyle et al (2010) in the 1990s to describe a type of learning that has a dual focus by using both second and foreign language learning to teach non-linguistic materials. CLIL has two distinct features that separate CLIL from other learning types such as immersion class (Gajo, 2002, Lasagabaster, 2009, Coyle 2007).

The first feature is the merging of language and non-language content. In CLIL, two elements are combined and have the same focus ratios, although each implementation is different. Because the ultimate goal is to improve the skills in these two fields, so not just teaching non-language materials in using a foreign language. The second feature is the flexibility that CLIL has to accommodate a wide variety of sociopolitical and cultural contexts in various places. 
The theoretical basis of CLIL as proposed by Coyle et al (2010) is the use of the $4 \mathrm{Cs}$ framework that is combining aspects of content, communication, cognition, and culture. The 4Cs framework is elaborated into the following principles:

1. Content: the focus of content and language integrated learning is that learners can construct knowledge and develop their skills independently

2. Cognition: that content is related to cognition. In order for the learner to construct knowledge, the linguistic demands of the content must first be analyzed.

3. The learned language should be contextual, should be able to facilitate the process of learning content through the language, can be used as a suggestion to construct content and related cognitive processes.

4. Interaction within the context of learning is important.

5. Intercultural awareness is fundamental to CLIL.

Moreover, Coyle et al (2010) argues that the effectiveness of CLIL depends on five factors, namely: the advancement of knowledge, skills, and understanding of learning materials, the application of cognitive processes.

Some researchers have applied CLIL in various fields of study with various results. Schleppegrell \& Achugar (2003) conducted research on the application of CLIL to the field of history studies, especially reading and writing. They conclude that language in history textbooks can be very difficult for language learners and they recommend teaching history should be followed by teaching grammatical features taught explicitly to learners e.g learners should be taught the types of verbs when reading textbooks.

The next researcher who investigated CLIL who also advocated instructions explicitly was Nussbaum (2002). The application of Nussbaum's (2002) research was through the implementation of genre-based writing to teach the field of history studies combined with graphic organizers. Nussbaum (2002) draws the conclusion that graphic organizers will be more useful to learners when combined with explicit language teaching.

The Conclusions and recommendations suggested by Schleppegrell \& Achugar (2003) and Nussbaum (2002) are appropriate for CLIL-based learning, but explicit language teaching should be contained in an explicit analysis framework so learners can digest the grammatical features they learn more easily.

\section{Systemic Functional Linguistics}

Systemic functional linguistics (SFL) is a branch of linguistics developed by Halliday (1994). Systemic functional linguistics is also an approach to linguistics that assumes a language as a social semiotic system. SFL approaches the language through questions, 1) how is the language used? and 2) how is the language structured for use? The answer to the first question involves focusing on authentic social interactions. The analysis considers that when humans interact, humans negotiate text to create meaning. Thus, the general function of the language is semantic.

In interpreting functional questions in a semantic way, systemic experts ask the question: 1) can various types of meaning in language be distinguished? for example how much meaning can we make when using language ?; 2) how is the text structured so that meaning can be created? Examples of how the language is organized so that it can create meaning. 
Halliday (1985a, 1985b) argues that language is structured to make three kinds of meanings simultaneously. The semantic complexity, which can realize the experiential, interpersonal, and textual meaning to be one in a single linguistic, can be formed because language is a semiotic system, which means that language is a conventional coding system and is structured as a set of choices. The semiotic interpretation of the language system results in the accuracy or inappropriateness of language usage in any context of use, and views language as a resource for creating meaning, having a particular purpose in a social context in which it is used. Therefore, SFL views that there is a relationship between text and context. The precision of the meaning of a text depends on the context in which the text is used. Without context, a text will not be meaningful or ambiguous. The context itself is in the text (Eggins, 1994). Halliday and Hassan (1990) divide the context into the context of the situation and cultural context.

\section{Context of Situation}

The context of the situation can be defined as anything that goes beyond the text (Halliday and Hassan, 1990). The context of the situation consists of three components: 1) the field that refers to what is happening), 2) the tenor which means the social relationship between the participants in the text, and 3) the mode which relates to the use of language, both oral and written. The relationship between text and situation context can be illustrated as follows;

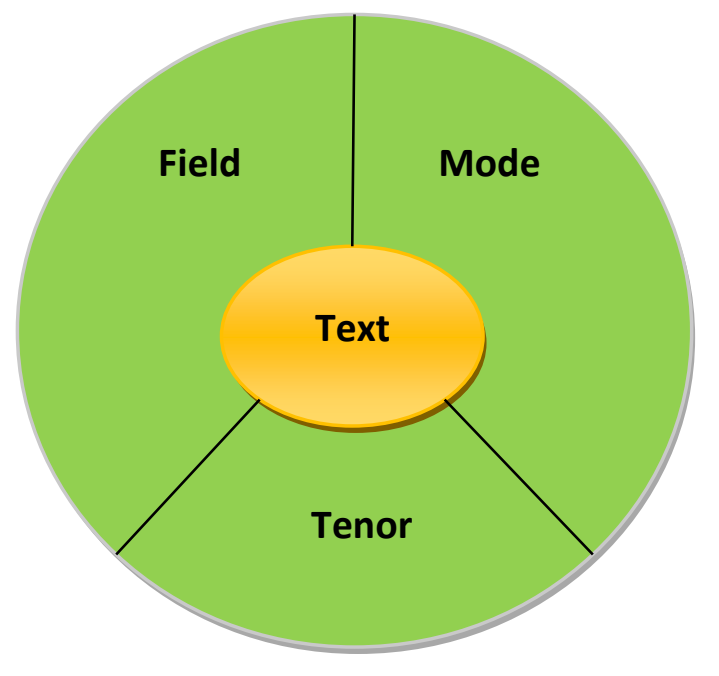

\section{Figure 1. Parameters of context of situation Source: Butt (1995:4)}

These three components are aspects that exist within our social context that affect the use of language. Contextual configuration is required to realize these three components. The following is a more specific explanation of the three components of a context of situation;

\section{Field}

Field is the subject of what is being discussed (Eggins, 1994). For short, the field is the topic of the text. Martin (1984) made it clear that field is a type of social activity that uses language as a companion of actions undertaken in the activity. For simplicity, the field can be defined as what is going on outside the text that includes the focus (the 
nature of social activity) and the object's focus (subject). So the function of the field is to make specific what events are going on (Gerot and Wignell, 1994)

\section{Mode}

Mode refers to how language is used, whether as an oral or written communication tool and whether language is used as a form of reflection (Gerot and Wignell, 1994). As language moves from action to reaction, there is a progressive gap between the actual event and the real experience. Some types of distances that refer to the language and the situation are spatial / interpersonal and experiential.

\section{Tenor}

The initial definition of tenor is the social role relationship played by the participants (Eggins, 1994). Social relationships between participants are dependent on: 1) authority status (agent, peer in hierarchical order, 2) affective affinity (preferred degree, dislike, or neutrality), and 3) contact (frequency, duration, intimacy of social contact).

Three components of the context of the situation explain our intimate understanding of the differences in the use of language when we are speaking or writing (mode), talking to our boss or our spouse (tenor), and talking about linguistics or instructions (field).

\section{Context of Culture}

The cultural context determines what we mean in our texts such as identity, behavior, and speech (Gerot and Wignell, 1994). The concept of genre is used to describe the impact of cultural contexts on language, by describing an institutionalized step-by-step structure as a means of gaining purpose through the use of language.

\section{Systemic Functional Linguistics-based Teaching}

The derivation of SFL used for teaching is a genre-based teaching (Martin \& Rose, 2005). In a genre-based teaching framework, the use of SFL for the teaching of academic languages emphasizes the deconstruction of linguistic structures so that what is expected to appear in academic texts can be seen clearly by learners (Aguirre Munoz, 2008).

Genre-based teaching emphasizes the importance of genre in academic text which is taught explicitly. In teaching academic texts, in accordance with the SFL, genre-based teaching divides academic texts into 1) field, which refers to how thought is expressed through content words such as participants (groups of nouns), processes (verbal), and adverbial expressions. The relationships between ideas in the field are created through connector between sentences and clustering strategies, 2) tenor refers to participants and relationships among participants in a text, 3) a mode which means the way of delivering the language either through oral or written.

Martin \& Rose (2005) divided genre-based teaching into three phases: 1) deconstruction, 2) joint construction, and 3) individual construction. The deconstruction phase begins with modeling that will explore one genre of a text. The joint construction phase involves students in writing text based on the genre being discussed. The individual construction phase gives students the responsibility to be able to write text independently based on the genre of the text discussed. Each phase involves developing 
a field of discussion and context, where students construct the content of the text genre and study the context in which the text is applied.

Here is an illustration of genre-based teaching:

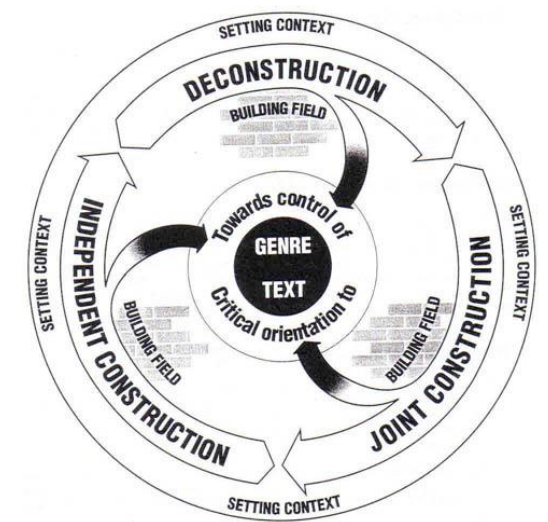

Figure 2. Genre Pedagogy Cycle (Martin \& Rose, 2005)

The figure explains the importance of various aspects of teaching through interaction within the context of shared experience during the process of writing text. Shared experiences are realized through setting goals of the genre text, field development, and context, interaction is the key element of teaching and learning especially in the joint construction phase. The details of the roles and functions of teachers and students in genre-based teaching are made clearly by Bernstein's term, that is classification which refers to the degree of freedom, authority, and limitations in the processing of content and framing which means the various options available to teachers in controlling what should be taught and what should be accepted by students in a pedagogical context (1975). For Berstein (1975), weak classification and framing are characterizations of the invisible pedagogy (as found in current progressive education); while strong classification and framing are characterizations of visible pedagogy.

The purpose of genre-based teaching is to combine the power of the two pedagogical streams. The deconstruction phase begins with weak classification and framing where the lecturers facilitate the initial activity; the goal is to explore the new field being studied and the context of the genre text being taught, then the framing and classification strengthen when the model of the text is introduced by the teacher where the teacher explicitly deconstructs the text by looking at the structure and purpose of the text. Joint construction begins with a weak classification and framing where students start brainstorming new ideas in the text before the teacher gives guidance to organize the ideas, in this phase the value of the framing power level is divided into two: 1) classification, where the students have more control and authority in processing text content and 2) framing, where teachers have more control in guiding the making of text. The independent construction phase begins with weak classification and framing as students begin exploring new fields; when they start making their own text, framing is still weak, but the classification gets stronger on the field and genre. The final phase of this stage emphasizes the creativity of students to cultivate the text genre they are learning (Martin \& Rose, 2005). 


\section{RESEARCH METHOD}

This study used a qualitative descriptive approach in order to provide an overview of the implementation of Content and Language Integrated Learning which is based on Systemic Functional Linguistics practiced within a tennis bilingual class. A qualitative descriptive approach was conducted so that this research could produce a detailed picture about the implementation of Content and Language Integrated Learning which is based on Systemic Functional Linguistics. The participants of this study were the $2^{\text {nd }}$ year undergraduate students of Sport Science Department of UNNES that were registered in bilingual class and comprised 20 students, academic year 2016/2017. They would answer an open and a closed questionnaire on the last lecturing day to obtain the information dealing with CLIL implementation.

The data used for this study were collected through several stages:

1. Observation

Observations would be performed during the classroom using audio and video recorder. The observation was focused on the steps undertaken by the lecturer in implementing Content and Language Integrated Learning based on Systemic Functional Linguistics.

2. Interview

The interview was organized to both lecturer and students of tennis class to support the data obtained from the observation. Interview is aimed to know the opinion of the students towards the implementation of Content and Language Integrated Learning based on Systemic Functional Linguistics in Tennis class.

3. Questionnaire

The questionnaires used in this study are divided into two: 1) closed questionnaires containing yes or no statements, and 2) open questionnaires used to check student attitudes and opinions on the implementation of Content and Language Integrated Learning based on Systemic Functional Linguistics.

\section{RESULTS AND DISCUSSION}

\section{How CLIL based on systemic functional linguistics can be implemented in a tennis bilingual class?}

To support the learning process, lesson plan had been prepared by the lecturers as the basis for the implementation of learning. The lesson plan was based on learning rules related to Systemic Functional Linguistics. The lesson plan divided learning process into three main activities: a) deconstruction, the purpose is to explore the new field being studied and the context of the texts genre being taught. In this activity the lecturer performs text deconstruction by looking at the structure and purpose of the text, b) Joint construction, where students start brainstorming new ideas in the text before the instructor provides guidance for organizing the ideas, and c) independent construction, where students begin exploring new fields; when they start making their own text. The final phase of this stage emphasizes the creativity of students to cultivate the genres of the text they are studying.

The followings are the steps of implementing CLIL witihin tennis class at fourmeeting classes;

1. First meeting

The first meeting began with the most basic tennis groundstroke, the forehand groundstroke. To support the teaching of the content, the lecturer provided an 
English material of action verbs. The learning process was divided into three stages: a) deconstruction, b) joint construction, and c) individual construction. In the deconstruction phase, the division of verbs in English is explained to the subject of the study and then they were explained the differences between the groups of verbs and focused on the action verbs that are useful for supporting the teaching of forehand groundstroke material. Research subjects were given exercises to differentiate and categorize the types of verbs that exist in English. Once the verbs are categorized and samples of the action verbs are collected, the research subjects demonstrated the action verbs physically. Action verbs are the basis of the forehand groundstroke movement. The material of the forehand groundstroke starts by modeling the action verbs for example "hold the racket at contact point (out in front, string facing forward and tip to the side), swing the racket forward from the contact point, push the incoming ball, then finish the racket over the opposite shoulder". Then it was continued with a material explanation of further forehand groundstroke. In the deconstruction stage, teacher's talk is more widely practiced than the students 'practice because the material explanation needs to be done before the students' practice.

The joint construction phase focuses more on the material practice of forehand groundstroke in groups. This stage reduces the portion of teacher's talk to explain the material. Instructors provide guided practice for forehand groundstroke through the game. The students practiced forehand groundstroke with the instructor through a one-shot mini tennis game. Research subjects were accompanied to be able to do the forehand groundstroke correctly. Feedback was given to students when they practiced doing forehand groundstroke.

Individual construction phase gives more chances to practice forehand groundstroke to individual students accompanied by instructors. The practice of individual construction is more focused on increasing the individual ability of the student to do forehand groundstroke.

2. Second Meeting

The deconstruction stage at the second meeting began with a review of the lesson at the previous meeting. Action verbs already taught at the first meeting are reviewed in the first 2 minutes. Action verbs were then developed again into imperative sentences in English. The structure of imperative sentences introduced to the students and how to arrange the action verbs into the imperative sentence. An example of using imperative sentences was also shown through a tennis-themed video so that the students understood the context in which the imperative sentence was used. After the example was given, students are given words that were still random, and they were asked to arrange the sentence into the correct imperative sentence.

The task of organizing correct imperative sentences was done in groups at joint construction phase. After the imperative sentences were arranged in groups, the sentence was practiced using the total physical response method. The instructor recites an imperative sentence made by the students then the students demonstrated the imperative sentence physically in a group. By physically demonstrating the imperative sentence, the students would understand better the imperative sentence they wrote.

In the individual construction phase, the instructor demonstrates the forehand groundstroke technique. Students write imperative sentences based on the movement they are demonstrating. This individual construction stage focuses on the mastery of 
imperative sentence and forehand groundstroke techniques of each individual. Here are the samples of imperative sentences performed by the students;

"bring your racket back parallel with your shoulders"

"place your racquet perpendicular to your body"

"Make sure your head stays down and your shoulders and feet stay perpendicular to the net"

"do not look up to where you are aiming because you will not hit the ball cleanly"

"Swing forward the racket to meet the contact point with the ball"

"Continue your swing motion until the racquet is over your left shoulder"

\section{Third Meeting}

The deconstruction phase at the third meeting began with a review of the lesson at the previous meeting of the imperative sentence. The review continued with the discussion of procedure text. The discussion on procedure text includes 1) the purpose of the procedure text and 2) the structure of the procedure text. The focus of this deconstruction stage is how to make procedure text from imperative sentences. An example of a taught procedure text talks about how to do a backhand groundstroke. When the text of the procedure text about the backhand groundstroke is displayed, the instructor demonstrated the movement of the backhand according to the order in the procedure text. Some instances of the procedure text are as follows; How to Get a Powerful Two-handed Backhand in Tennis:
a. Racket
b. Balls
c. Net

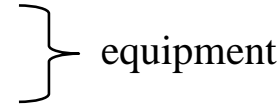

Steps:

1) Turn your body perpendicular to your opponent

2) Put your hands in a two-handed grip

3) Keep the racket face above your hands

4) Plant your right foot forward

5) Wind back from the shoulders

6) Transfer your weight to your back leg

7) Drop the racket into the slot

8) Lift as you swing forward

9) Transfer your weight forward

10) Contact the ball around waist height just in front of your forward hip

11) Maintain eye contact with the point of connection

12) Swing through without lunging

The understanding of procedure text is balanced with an understanding of how to do backhand groundstroke by demonstrating it in groups at the joint construction phase. At this phase, the instructor demonstrated and spoke the steps in the procedure text and also asked the students to follow it. Instructors provided feedback on the suitability of student's movement by performing a backhand on the procedure text.

Coming to individual construction phase, the lecturer/instructor provided groundstroke drills to individual student to train backhand shots accompanied by instructors. After a while, the students were paired with each other then practiced 
their backhand groundstroke. One student gave instruction in English in accordance with the procedure text, and the other students demonstrated. After all the stages in the procedure text were done then students swap roles to demonstrate.

4. Fourth Meeting

Within the fourth meeting, the deconstruction phase begins with a review of the lesson that has been done before that is procedure text. The discussion on the procedure text followed by showing a video demonstrating tennis serves on tennis court. One by one the movement on the video is discussed and performed by the instructor either orally or in motion. When the instructor displays the existing serve movements of the video, the subject of the study is asked to record the imperative sentences spoken verbally by the instructor. The points of doing tennis serve can be shown as follows:

How to Serve in Tennis:

$\begin{array}{ll}\text { a. } & \text { Racket } \\ \text { b. } & \text { Balls } \\ \text { c. Net } & \text { Nequipment }\end{array}$

Steps:

1) Get in position

2) Grip the ball and racket correctly

3) Toss the ball and bring racket behind you

4) Scratch your back with the racket

5) Hit the ball with "the sweet spot" of the racket

6) Hit the ball at its highest point

7) Follow through by bringing your racket down near the bottom of your opposite foot

8) Fall into the court after you serve

9) Do not cross the service line before you make contact with the ball

The students were then asked to work in groups at the joint construction phase. They compared the imperative sentences they had previously recorded individually. Feedback was given by the instructor so that the imperative sentence was recorded according to the motion presented in the video. The instructor subsequently asked the students to compile the imperative sentences into a procedure text about the serves on the tennis court. Feedback was given by the instructor so that the procedure text of the group discussion results met the rules of procedure text and in accordance with the stages of how to do tennis serves.

Afterwards, the procedure text results from group discussions are then used as guidelines for students to perform tennis serves. Individual tennis serve drills then given to the students. Each of student did tennis serve in accordance with the steps written in the procedure text with the accompaniment of the instructor. Feedback is given by the instructor so that the serve technique is appropriately performed by each research subject. 


\section{Students' Response towards the Implementation of CLIL}

Gaining students' and lecturer's response towards the implementation of CLIL within tennis class was one of the points that the researcher wanted to get. The data was obtained through questionnaire and interview with bilingual students.

There would be open and closed questionnaire spread to the students. The questionnaire comprised 17 closed questions and 6 open questions. After the questionnaires were distributed to 20 students, the results of the closed questionnaire 1 can be seen through the table as follows:

\begin{tabular}{|c|c|c|c|}
\hline Number & Question & $\begin{array}{l}\text { Yes } \\
(\%)\end{array}$ & $\begin{array}{c}\text { No } \\
(\%)\end{array}$ \\
\hline 1. & $\begin{array}{l}\text { Have you ever taken Intensive English course prior to } \\
\text { coming to college? }\end{array}$ & 20 & 80 \\
\hline 2. & $\begin{array}{l}\text { Did UNNES require you to take English proficiency } \\
\text { test (TOEFL, IELTS, TOEIC) on the registration } \\
\text { process? }\end{array}$ & 0 & 100 \\
\hline 3. & $\begin{array}{l}\text { Have you ever taken official English proficiency test } \\
\text { (TOEFL, IELTS, TOEIC)? }\end{array}$ & 30 & 70 \\
\hline 4. & $\begin{array}{l}\text { Are there any subjects taught in English instead of your } \\
\text { native language in your previous class except an } \\
\text { English class? }\end{array}$ & 30 & 70 \\
\hline 5. & $\begin{array}{l}\text { Did you feel that your English is good enough, so you } \\
\text { decided to join with a bilingual class }\end{array}$ & 35 & 65 \\
\hline
\end{tabular}

From table 1, it can be seen in the question point one that $80 \%$ of bilingual class students did not prepare for special English training before studying at UNNES, while only $20 \%$ of students who prepared themselves with intensive English training before entering this University. Then, point two shows that none of the bilingual class students stated that UNNES wants them to have TOEFL / IELTS / TOEIC certificate before they study at UNNES as a requirement to be accepted as either Darmasiswa or other international programs students. The third point in the questionnaire shows that only $30 \%$ of bilingual class students who has certificate of English Proficiency Test and $70 \%$ of students do not have them. While point four indicates that $30 \%$ students used to get a lecture with English as the instructional language in the previous class and $70 \%$ were never taught in English for subjects rather than English course. The last point reveals the students' confidence of their own English skills. We can see that only $35 \%$ students believed that they have good enough English, so they are confident to take bilingual class, whereas $65 \%$ students are not sure about their English skill.

According to data shown on Table 1, the researchers found that most bilingual students who have the opportunity to study at UNNES were not prepared to master English as an international language before officially taking courses at UNNES. This is because the students generally have a lack of motivation and willingness to master English as a foreign language. In addition, UNNES does not require applicants to have skills in English as a prerequisite to be accepted as a student. Therefore learning by using CLIL method within tennis is very necessary to bridge the miscommunication between lecturers and students considering that most students' English skills are limited. 
To find out the extent of the students' experience in following tennis class by using CLIL method, the researcher gave a closed questionnaire to students 2 to get ideas how the application of CLIL method contributes to the learning process. The results of the closed questionnaire 2 can be seen in the following table:

Table 2. Closed questionnaire 2

In relation to students' experience in following the class

\begin{tabular}{|c|c|c|c|c|c|c|}
\hline Nb. & Question & $\begin{array}{l}\text { Strongly } \\
\text { Agree } \\
(\%)\end{array}$ & $\begin{array}{c}\text { Agree } \\
(\%)\end{array}$ & $\begin{array}{l}\text { Undecided } \\
(\%)\end{array}$ & $\begin{array}{l}\text { Disagree } \\
(\%)\end{array}$ & $\begin{array}{l}\text { Strongly } \\
\text { disagree } \\
(\%)\end{array}$ \\
\hline 1. & $\begin{array}{l}\text { English as the instructional } \\
\text { language was spoken fluently } \\
\text { and clearly by the instructor }\end{array}$ & 70 & 20 & 5 & 5 & 0 \\
\hline 2. & $\begin{array}{l}\text { The fluency of the instructor in } \\
\text { using English language } \\
\text { influences my understanding of } \\
\text { the subject matter }\end{array}$ & 20 & 65 & 5 & 10 & 0 \\
\hline 3. & $\begin{array}{l}\text { My English skills helps me to } \\
\text { understand the subject matter } \\
\text { despite the instructor's fluency }\end{array}$ & 15 & 50 & 20 & 15 & 0 \\
\hline 4. & $\begin{array}{l}\text { My prior knowledge of the } \\
\text { subject matter helps me to } \\
\text { understand the subject taught in } \\
\text { English }\end{array}$ & 0 & 30 & 15 & 30 & 15 \\
\hline 5. & $\begin{array}{l}\text { The instructor's gestural } \\
\text { modelling of the subject helps } \\
\text { me to understand the subject }\end{array}$ & 70 & 20 & 5 & 5 & 0 \\
\hline 6. & $\begin{array}{l}\text { The group work helps me to } \\
\text { understand the subject }\end{array}$ & 35 & 55 & 10 & 0 & 0 \\
\hline 7. & $\begin{array}{l}\text { The individual practice helps me } \\
\text { to understand the subject }\end{array}$ & 25 & 50 & 10 & 15 & 0 \\
\hline 8. & $\begin{array}{l}\text { The lesson Scaffolding helps me } \\
\text { to understand the subject matter }\end{array}$ & 30 & 65 & 5 & 0 & 0 \\
\hline 9. & $\begin{array}{l}\text { The lesson Scaffolding helps me } \\
\text { to understand the English } \\
\text { language }\end{array}$ & 15 & 70 & 10 & 5 & 0 \\
\hline 10. & $\begin{array}{l}\text { I learn English language better } \\
\text { in CLIL }\end{array}$ & 50 & 45 & 0 & 5 & 0 \\
\hline 11. & $\begin{array}{l}\text { I learn the subject matter better } \\
\text { in CLIL }\end{array}$ & 25 & 65 & 5 & 5 & 0 \\
\hline 12. & $\begin{array}{l}\text { I feel comfortable being taught } \\
\text { using CLIL }\end{array}$ & 20 & 75 & 0 & 5 & 0 \\
\hline
\end{tabular}

Based on the data obtained and shown in table 2, the researchers found that the students considered that the teachers have good English skills and the lesson are easy to comprehend so that the students are able to follow tennis class well. There were only six students who had learned tennis before joining the class. As many as $50 \%$ of students believed with certainty that in addition to learning tennis they also learn English such as enriching vocabularies associated with tennis lessons. Furthermore, as many as $90 \%$ assume that teachers have best tennis skills so they can play a good role model on the courts. It is believed by $85 \%$ that the fluency and clarity of the lecturer in delivering the material can facilitate them to understand the taught lesson better. 
Meanwhile, to get a more detailed picture of CLIL implementation in tennis class, the researchers provided an open questionnaire and interview to bilingual students at the end of the class. These are samples of the data obtained as follows:

1) Some of the bilingual class students agree that CLIL should be implemented in each subject regarding English is an International language which can lead to professionalism. They also believe that through learning by using CLIL they would be able to add information about vocabularies in English, language structure, etc.

Questions: How do you respond towards the implementation of Content and Language Integrated Learning?

Answers:

"It's a very nice way for your students to improve their English language, but I think many of the students at UNNES have problems when speaking English, so the English language can be difficult for them to understand".

"I think it is a really good idea".

"I think it is a good way of learning. For me it is important to get exposed to a lot of language in order to pick up new words, word patterns, structures etc, and content and language integrated learning helps me getting exposed to a lot of English".

2) Most students argue that CLIL implementation in the English language course provides a balanced proportion of learning English with tennis lesson. Students are able to follow any material given by the teacher either in the form of practice or theory.

Questions: Is the implementation of Content and Language Integrated Learning able to deliver the English language learning and the subject matter in balanced proportion? Please elaborate!

Answers:

"I think it is a bit more difficult to learn about a new subject/topic in other languages than my native language, so it demands more focus and concentration from the students side, in order to both understand the language AND the subject.

"Yes. I think it is important for the lecturers to find a good balance between teaching the theory in English and practice the theory by ourselves or in groups and I think the lecturer has delivered both well."

"Yes. Movement and language activities go well together towards improving both subjects".

3) The Students reveal that one of tennis lecturers have good English-speaking skill and good writing skill so that he can give good comprehension of materials to students

Questions: Do you think that the tennis lecturers have good and fluent English so it influence you to comprehend the lesson better? Please Elaborate!

Answers:

"I think the lecturer had great English skills".

"Definitely. It is important the instructor is able to give clear and understandable messages".

"Yes. It is important that you understand everything so you can prevent misunderstandings".

4) In general, $75 \%$ of bilingual class students who took tennis class were able to communicate using English considering that they got good score on English subject. They argue that their basic English skills would indirectly affect the ability 
of students to understand the lesson delivered by the lecturers. Some students seemed to have little difficulty in learning since their English skills were not good enough. However, the teacher still facilitates the students in particular in order to develop either skill or theory.

Questions: Do you think that your English skills influence your understanding of the subject matter during the implementation of Content and Language Integrated Learning? Please Elaborate!

Answers:

"Of course. My skills decide whether I understand or not. I won't learn anything if I don't understand what is said".

"Yes. If you can't communicate you can easily have miscommunications and it can be difficult to learn the theory behind Tennis".

"Yes. I would not be able to understand, if my English skills wasn't good".

5) Most of the students have never played tennis. It indirectly affects their readiness in learning new science. Teachers patiently made efforts to provide material simultaneously both in theory and practice. Students assume that it would be easier to follow lectures when they have had experience in playing tennis or at least understand basic knowledge in playing tennis

Questions: Do your prior knowledge of tennis play more role in your understanding about the subject? Please elaborate!

Answers:

"It plays a role but it can be changes if I learn something new about the subject".

"No. I didn't know much about tennis before". If I had known before it would have been much easier to understand and play now".

"Definitely. The basic understanding of how Tennis is played and what I have previously played and learned influences my performance in class".

6) Most of the students enjoy playing tennis classwork with CLIL implementation. They feel that there would be no difficulty both in theory and practice if they enjoy the lectures given by the teacher. However, there are some difficulties faced by students that need to be facilitated, such as the difficulty in practicing every movement technique in tennis because not all students have good psychomotor intelligence and the concentration level of students who tend to decrease when they are tired.

Questions: What was your main difficulty during the implementation of Content and Language Integrated Learning?

Answers:

"To stay concentrated. It can be exhausting to both concentrate on understanding the language AND learn about the content".

"To control the ball and find the right amount of power".

"I didn't really have any difficulties with the implementation of CLIL. I did, however, have difficulties learning and practicing the strookes"

\section{CONCLUSION}

Content and Language Integrated Learning based on Systemic Functional Linguistics can provide a balanced portion for learning English and course content which is taught. A balanced portion of teaching between English and course content is obtained by selecting appropriate English language material that can support the subject lesson, for instance learning through action verbs dealing with practicing forehand and 
backhand groundstroke as well as serve lesson on the tennis court. The addition of the systemic functional linguistics element of the genre can make it easier for students to understand the content in a text structure coherently and systematically. Material that is arranged systematically on a certain text genre, for example procedure text, can make it easier for students to figure out the content material. The integration of Systemic Functional Linguistics not only contributes to the preparation of material in a text genre but also provides lesson scaffolding in three phases: 1) deconstruction, 2) joint construction, and 3) individual construction. These phases offer students the opportunity to learn the material actively in groups or individuals. Students are given a wider chance to practice on the material being taught.

\section{REFERENCES}

Bernstein, B. 1975. Class, Codes, and Control Volume 3: towards a Theory of Educational Transmissions. London: Routledge and Kegan Paul.

Butt, D.R, Fahey S. Spinks and C, Yallop. 1995. Using Functional Grammar: an explorer's guide. Sydney: Macquirie University, NCELTR

Cohen, A. 1975. A Sociolinguistic Approach to Bilingual Education. Rowley, Mass.: Newbury House.

Collier, V., and C. Ovando. 1985. Bilingual and ESL Classrooms: Teaching in Multicultural Contents. New York: McGraw Hill.

Coyle, D. (2007).'Content and Language Integrated Learning: Towards a Connected Research Agenda for CLIL Pedagogies. The International Journal of Bilingual Education and Bilingualism.10 (5), 543-562.

Coyle, D., Hood, P., \& Marsh, D. 2010. CLIL: Content and language integrated learning. New York, NY: Cambridge University Press.

Eggins, S. 1994. An Introduction to Systemic Functional Linguistics. London: London Press

Finnochiaro, M., \& C. Brumfit. 1983. The Functional-Notional Approach: from Theory to Practice. New York: Oxford University Press.

Gajo, L.y Serra, C. 2002. Bilingual teaching: Connectinglanguage and concepts in mathematics. EnD. So / G. Jones (eds.). Education and Society in Plurilingual Contexts. Brussels: VUB Brussels University Press, páge.75---95.

Gerrot, W and Wignell P. 1994. Making Sense of Functional Grammar. Cambridge: Gerd Stabler.

Halliday, M.A.K. 1994. An introduction to functional grammar (second edition). London: Edward Arnold.

Halliday, Michael A.K. \& R. Hasan. 1990. Language, context, and text: aspects of language in a social-semiotic perspective. Oxford: Oxford University Press.

Lasagabaster, D. 2009. The Implementation of CLIL and attitudes towards trilingualism. International Journal of Applied Linguistics, 157, 23-44.

Martin, J.R. 1984b. Lexical Cohesion, Field, and Genre: Parceling Experience and Discourse Goals. In Volume 3 in the Collected Works of J.R. Martin, ed. Z. Wang, 31 - 64. Shanghai: Shanghai Jiao Tong University Press. 
Martin, J.R., \& Rose, David. 2005. Designing Literacy Pedagogy: scaffolding assymetries. In J Webster, C. Mathiessen \& R. Hasan (eds.). Contnuing Discourse in Language. London: Continuum, 2005, 251 -280.

Munoz, Z. 2008. Developing Teacher Capacity for Serving ELLs' Writing Instructional Needs: A Case for Systemic Functional Linguistics. Bilingual Research Journal 31(1-2):295-322.

Nussbaum, M. 2002. Education for Citizenship in an Era of Global Connection. Studies in Philodophy and Education, 21, 289-303, doi: 10.1023/A: 1019837105053.

Rubtcova, M. \& Valentina K. 2016. Implementation of Content and Integrated Learning (CLIL) Programmes in Public Administration: Russian Students' and Matriculants' Opinion about their First CLIL Experience. Teaching Public Administration Journal, Vol 34(3) 229-246.

Schleppegrell, M., Achugar, M., \& Orte'1za, T. 2004. The Grammar of History: Enhancing

Content-based Instruction through a Functional Focus on Language. TESOL Quarterly $38,67-93$ 